\title{
Primary hyperparathyroidism in a patient with Conn's syndrome
}

\author{
A. Fertig \\ M.B. \\ M. WeBLeY \\ M.B., M.R.C.P. \\ J. A. LYNN*
M.S., F.R.C.S. \\ Department of Chemical Pathology, Medicine and Surgery, \\ Westminster Hospital, London SWIP 2AR
}

\begin{abstract}
Summary
A 61-year-old patient with treated Conn's syndrome due to multiple bilateral adrenocortical adenomata developed primary hyperparathyroidism. At operation, a parathyroid adenoma and a thyroid colloid nodule were found. Although adrenocortical adenomata and hyperplasia are common findings in multiple endocrine adenopathy type I, they are only rarely functional. Hypertension is often associated with primary hyperparathyroidism, but the relationship is usually unexplained.
\end{abstract}

\section{Introduction}

Multiple endocrine adenopathy (MEA) type I usually consists of 2 or more of the following: primary hyperparathyroidism, pancreatic islet cell tumour, pituitary adenoma and adrenocortical adenoma (Wermer, 1963). Various types of thyroid gland disorder may be associated with the syndrome, and lipomata and bronchial carcinoid tumours may also occur. The adrenocortical adenomata are rarely functional and the finding of a parathyroid adenoma with Conn's syndrome appears to be extremely uncommon.

\section{Case history}

A 51-year-old female civil servant presented in 1967 with a 6-year history of increasing tiredness, weakness, nocturia, a moderate degree of dyspnoea on exertion, and occipital headaches, worse on waking in the morning. She had been on no drug treatment until 3 weeks before admission when she had been started on $25 \mathrm{mg}$ hydrochlorthiazide and $8 \mathrm{mmol}$ potassium chloride daily. She had no diarrhoea or vomiting and had been on a normal diet. On examination, her BP was $260 / 160 \mathrm{mmHg}$, there was evidence of left ventricular hypertrophy, confirmed electrocardiographically and radiologically, and a grade III hypertensive retinopathy.

On investigation, plasma findings included:

* Present address: Hammersmith Hospital, London W12. sodium, $153 \mathrm{mmol} / \mathrm{l}$; potassium, $1.7 \mathrm{mmol} / \mathrm{l}$; total $\mathrm{CO}_{2}, 39 \mathrm{mmol} / 1$; urea, $6.0 \mathrm{mmol} / \mathrm{l}$; total protein, $66 \mathrm{~g} / \mathrm{l}$; calcium, $2.60 \mathrm{mmol} / 1$ (reference range 2.00 $2.55 \mathrm{mmol} / \mathrm{l})$; inorganic phosphate, $0.63 \mathrm{mmol} / 1$ (reference range $0.73-1.39 \mathrm{mmol} / \mathrm{l}$ ); alkaline phosphatase, $5 \mathrm{KAu}$. (reference range 1-17). There was no glycosuria or proteinuria, and microscopy and culture of the urine was normal. Daily urinary potassium and sodium losses were $80 \mathrm{mmol}$ and $125 \mathrm{mmol}$ respectively. Urinary 17 oxogenic steroid and vanillyl mandelic acid excretion were normal, as were an IVP and aortogram. Selective adrenal vein catheterization, however, showed the possible presence of a tumour in the right gland. On the basis of these findings a diagnosis of Conn's syndrome was made. About $1500 \mathrm{mmol}$ of oral potassium were required, over a 3-week period, to correct the potassium depletion. At laporotomy the right gland contained an oval cortical adenoma, $2.75 \times 1.5 \mathrm{~cm}$, and the left gland contained multiple cortical adenomata, and bilateral adrenalectomy was performed (Fig. 1). Postoperatively, she was given cortisone acetate replacement therapy. Gradually her BP returned to normal.

She remained well until 1977, when she was investigated for back pain. She still complained of tiredness and nocturia and had a tendency to constipation when not taking her daily bran. Clinical examination revealed no significant abnormalities. Plasma findings were: calcium, $2.96 \mathrm{mmol} / \mathrm{l}$; inorganic phosphate, $0.67 \mathrm{mmol} / 1$; total protein, 71 $\mathrm{g} / \mathrm{l}$; albumin, $33 \mathrm{~g} / \mathrm{l}$; urea, $9.6 \mathrm{mmol} / \mathrm{l}$; sodium, 134 $\mathrm{mmol} / \mathrm{l}$; potassium, $4.1 \mathrm{mmol} / \mathrm{l}$; total $\mathrm{CO}_{2}, 27$ $\mathrm{mmol} / \mathrm{l}$; alkaline phosphatase, $250 \mathrm{u}$. at $35^{\circ} \mathrm{C}$ (reference range 90-330 u.); $\mathrm{Hb}, 13.9 \mathrm{~g} / \mathrm{dl}$; ESR, 18 $\mathrm{mm} / \mathrm{hr}$. Radiological examination of the chest, vertebral column, skull and hands was normal. Other investigations including plasma thyroxine, calcitonin and gastrin were normal and the blood glucose was $4.0 \mathrm{mmol} / \mathrm{l}$ after a $16-\mathrm{hr}$ fast.

Neck exploration revealed an adenoma in the 


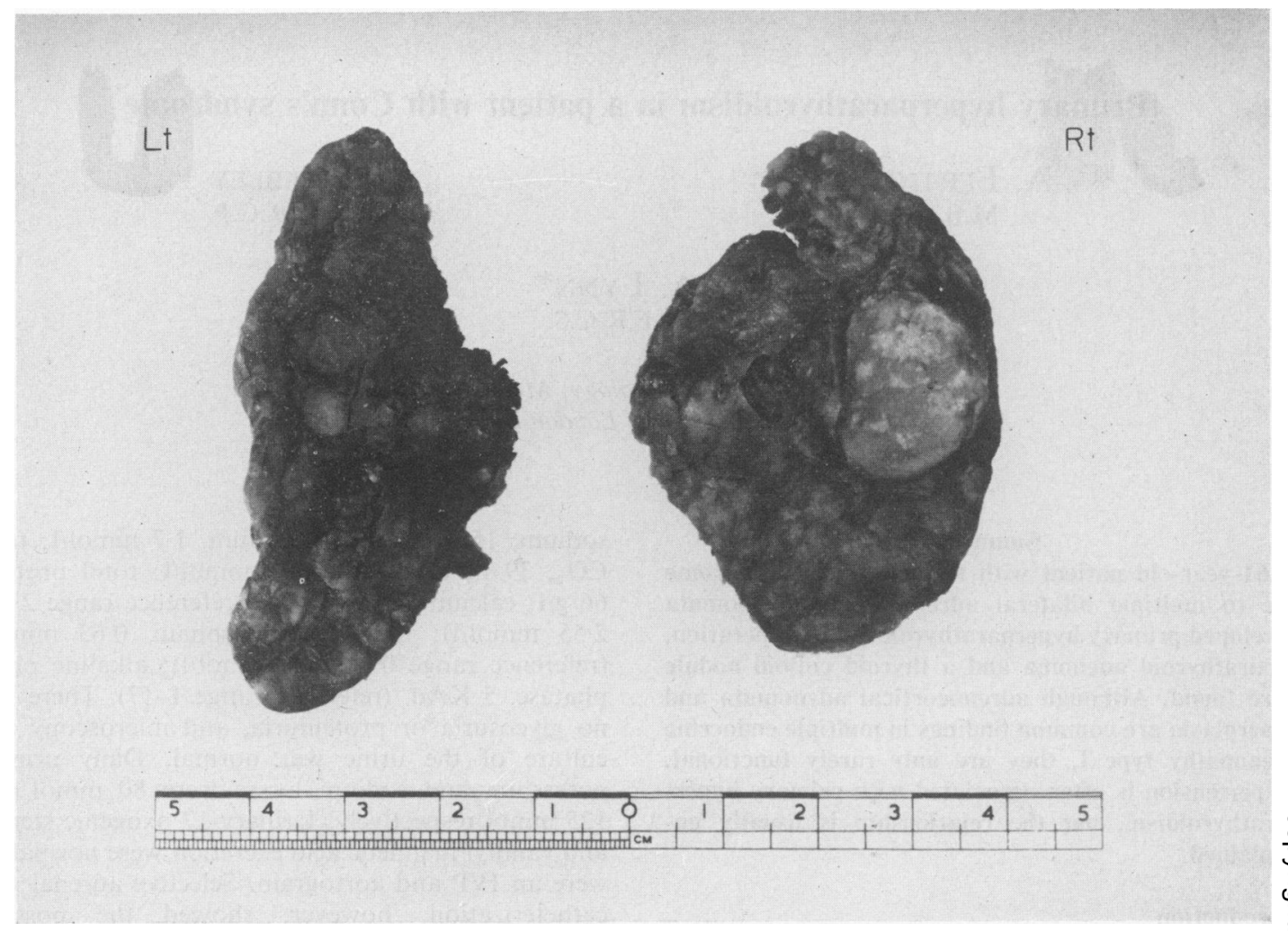

FIG. 1. Adrenal glands showing a large adrenocortical adenoma on the right gland, and multiple adrenocortical adenomata on the left.

upper left parathyroid gland, and a small colloid nodule in the left lobe of the thyroid gland, both of which were removed. Postoperatively, plasma calcium and phosphate concentrations returned to and remained normal.

One brother had died suddenly aged 47 years of a probable cerebrovascular accident. There was no other relevant family history. One sibling and an only child were found to have normal plasma calcium, phosphate, potassium and sodium concentrations. Four other siblings were unavailable for screening.

\section{Discussion}

Primary hyperparathyroidism is the most frequently occurring component of MEA type $I$. Histologically, there is a high incidence of multiple parathyroid adenomata and parathyroid hyperplasia, but a single adenoma was present in at least $25 \%$ of one series (Ballard, Frame and Hartsock, 1964). It is interesting to note that although the plasma calcium and phosphate concentrations in 1967 were only just outside their respective reference ranges, these results were almost certainly indicative of mild $\frac{\overrightarrow{\overrightarrow{0}}}{3}$ primary hyperparathyroidism at this time. The $\frac{\Im}{\vec{J}}$ gradual onset of this disease in many patients is well known (Tomlinson and O'Riordan, 1978).

Hypertension is a well described association of $\frac{0}{3}$ primary hyperparathyroidism occurring in up to one third of patients (Rosenthal and Roy, 1972). In the 3 . majority of cases the hypertension is not related to renal damage and the cause is unknown. In the present patient, the hypertension was associated with $\mathrm{O}$ a severe hypokalaemic alkalosis due to Conn's syndrome.

Most types of thyroid disease, including colloid nodule, adenoma, carcinoma, thyrotoxicosis and $\stackrel{N}{\sigma}$ Hashimoto's thyroiditis, have been described in a few $N$ patients with MEA type I (Craven, Goodman and N Carter, 1972; Wermer, 1963; Snyder, Scurry and ${ }_{\sigma}^{\omega}$ Deiss, 1972; Ballard et al., 1964). However, these findings are probably coincidental: up to $50 \%$ of one post-mortem series of clinically normal thyroid $\stackrel{\oplus}{\oplus}$ glands contained a thyroid nodule (Mortensen, Woolner and Bennett, 1955).

It seemed unlikely that the very short course of $\frac{\vec{D}}{d}$ 
diuretics would have produced the severe degree of potassium depletion; nor would it explain the high plasma sodium concentration. Causes other than Conn's syndrome were unlikely on clinical grounds. Renin and aldosterone studies were not performed probably because they were not readily available at that time. The histology of Conn's syndrome is usually that of a single adrenocortical adenoma, or occasionally hyperplasia. The finding of bilateral multiple adrenocortical adenomata is uncommon, occurring in less than $2 \%$ of cases in one series (Conn, 1961).

In a report and review of 85 cases of MEA type I, Ballard et al. (1964), found evidence of adrenocortical involvement in 31 patients. Cortical adenomata occurred in 12 patients, whilst diffuse and nodular hyperplasia accounted for the remainder. The significance of these findings was in doubt, however, as clinical or biochemical evidence of adrenocortical hyperfunction was unusual. An exception was a 15-year-old girl with evidence of hyperaldosteronism associated with hyperplastic adrenal glands, primary hyperparathyroidism and peptic ulceration. Although adrenocortical abnormalities may be found incidentally in up to one third of post-mortems (Heinbecker, O'Neal and Ackerman, 1957), adrenocortical adenomata occurred in only $2.9 \%$ of one large post-mortem series (Commons and Callaway, 1948).

Conn's syndrome due to an adrenocortical adenoma has been described in a patient with acromegaly from an acidophil pituitary adenoma (Dluhy and Williams, 1969). In addition, a functioning adrenocortical carcinoma producing Cushing's syndrome was reported in association with primary hyperparathyroidism (Raker, Henneman and Graf, 1962). Thus, although adrenocortical abnormalities are fairly common in MEA type I, hyperfunction is rarely detected. This association of Conn's syndrome with primary hyperparathyroidism may be a casual one, but probably represents a rare variant of MEA type I.

\section{Acknowledgments}

We thank Dr F. B. Gibberd and Mr G. Westbury for permission to report this case.

\section{References}

Ballard, H.S., Frame, B. \& Hartsock, R.J. (1964) Familial multiple endocrine adenoma-peptic ulcer complex. Medicine, 48, 481.

Commons, R.R. \& Callaway, C.P. (1948) Adenomas of the adrenal cortex. Archives of Internal Medicine, 81, 37.

ConN, J.W. (1961) Aldosteronism and hypertension. Archives of Internal Medicine, 107, 813.

Craven, D.E., Goodman, A.D. \& Carter, J.H. (1972) Familial multiple endocrine adenomatosis. Archives of Internal Medicine, 129, 567.

Dluhy, R.G. \& Williams, G.H. (1969) Primary aldosteronism in a hypertensive acromegalic patient. Journal of Clinical Endocrinology, 29, 1319.

Heinbecker, P., O’Neal, L.W. \& Ackerman, L.V. (1957) Functioning and nonfunctioning adrenal cortical tumors. Surgery, Gynecology and Obstetrics, 105, 21.

Mortensen, J.D., Woolner, L.B. \& BennetT, W.A. (1955) Gross and microscopic findings in clinically normal thyroid glands. Journal of Clinical Endocrinology and Metabolism, 15, 1270.

Raker, J.W., Henneman, P.H. \& Graf, W.S. (1962). Coexisting primary hyperparathyroidism and Cushing's syndrome. Journal of Clinical Endocrinology, 22, 273.

Rosenthal, F.D. \& RoY, S. (1972) Hypertension and hyperparathyroidism. British Medical Journal, 4, 396.

SNyder, N., Scurry, M.T. \& DeISS, W.P. (1972) Five families with multiple endocrine adenomatosis. Annals of Internal Medicine, 76, 53.

Tombinson, S. \& O'RIORdan, J.L.H. (1978) The parathyroids. British Journal of Hospital Medicine, 19, 40.

Wermer, P. (1963) Endocrine adenomatosis and peptic ulcer in a large kindred. American Journal of Medicine, 35, 205. 